OPEN ACCESS

Edited by:

Sonia Duprey,

Université de Lyon, France

Reviewed by: Anita Vasavada, Washington State University,

United States

John Henry Bolte, The Ohio State University,

United States

${ }^{*}$ Correspondence:

Peter A. Cripton

peter.cripton@ubc.ca

Specialty section:

This article was submitted to

Biomechanics,

a section of the journal

Frontiers in Bioengineering and

Biotechnology

Received: 23 March 2021

Accepted: 22 July 2021

Published: 17 August 2021

Citation:

Booth GR, Cripton PA and Siegmund GP (2021) The Lack of Sex, Age, and Anthropometric Diversity in

Neck Biomechanical Data.

Front. Bioeng. Biotechnol. 9:684217.

doi: 10.3389/fbioe.2021.684217

\section{The Lack of Sex, Age, and Anthropometric Diversity in Neck Biomechanical Data}

\author{
Gabrielle R. Booth ${ }^{1,2}$, Peter A. Cripton ${ }^{1,2 *}$ and Gunter P. Siegmund ${ }^{3,4}$ \\ ${ }^{1}$ Orthopaedic and Injury Biomechanics Laboratory, School of Biomedical Engineering and Departments of Orthopaedics and \\ Mechanical Engineering, University of British Columbia, Vancouver, BC, Canada, ${ }^{2}$ International Collaboration on Repair \\ Discoveries, University of British Columbia, Vancouver, BC, Canada, ${ }^{3} \mathrm{MEA}$ Forensic Engineers \& Scientists, Richmond, BC, \\ Canada, ${ }^{4}$ School of Kinesiology, University of British Columbia, Vancouver, BC, Canada
}

Female, elderly, and obese individuals are at greater risk than male, young, and non-obese individuals for neck injury in otherwise equivalent automotive collisions. The development of effective safety technologies to protect all occupants requires high quality data from a range of biomechanical test subjects representative of the population at risk. Here we sought to quantify the demographic characteristics of the volunteers and post-mortem human subjects (PMHSs) used to create the available biomechanical data for the human neck during automotive impacts. A systematic literature and database search was conducted to identify kinematic data that could be used to characterize the neck response to inertial loading or direct head/body impacts. We compiled the sex, age, height, weight, and body mass index (BMI) for 999 volunteers and 110 PMHSs exposed to 5,431 impacts extracted from 63 published studies and three databases, and then compared the distributions of these parameters to reference data drawn from the neck-injured, fatally-injured, and general populations. We found that the neck biomechanical data were biased toward males, the volunteer data were younger, and the PMHS data were older than the reference populations. Other smaller biases were also noted, particularly within female distributions, in the height, weight, and BMI distributions relative to the neck-injured populations. It is vital to increase the diversity of volunteer and cadaveric test subjects in future studies in order to fill the gaps in the current neck biomechanical data. This increased diversity will provide critical data to address existing inequities in automotive and other safety technologies.

Keywords: injury biomechanics, injury prevention, population diversity, neck, ageing, obesity, sex differences, anthropometric differences

\section{INTRODUCTION}

Injuries to the head and neck, which house and protect the brain and upper spinal cord, are some of the most catastrophic consequences of motor vehicle collisions. Over the past 7 decades, improvements in roads, vehicles, safety equipment, safety regulations, and enforcement have significantly reduced the injury, morbidity, and mortality burden associated with head and neck injuries. Despite these considerable achievements, many injury prevention approaches, including the computational models and anthropometric test devices (ATDs) used to design and evaluate safety equipment, have focused on 50th percentile adult male occupants (Linder and Svensson, 2019). As a 
result, females and others who fall outside the anthropometric envelope of this "median male" are not as well represented in automotive safety equipment design. Assuming that ATDs and other surrogates are appropriate for developing vehicle safety technology, it follows that considerable numbers of injured and killed occupants were using safety equipment that may not have been optimally designed for them.

European and United States traffic safety regulatory standards are used worldwide, with minor alterations, to assess a vehicle's ability to prevent serious injuries for the occupants and other road users. These standards specify the use of 50th percentile adult male ATDs and representations of the 95th percentile male and 5 th percentile female, which have been scaled from the 50th male by weight and height. While these three occupant representations attempt to approximate the median and extremes of height and weight of adult occupants, changes in size alone are not sufficient to represent the age, sex, and anthropometric variations seen in the population that safety technologies aim to protect (Linder and Svensson, 2019). Additionally, child restraint system performance evaluation is conducted using Hybrid III child dummies that were also derived from scalings of the Hybrid III 50th percentile adult male dummy and basic child anthropometry (Irwin and Mertz, 1997). Therefore, many ATDs used in traffic safety regulatory standards have been derived from a representation of a 'median-sized' adult male.

Anthropometry and size are not the only factors related to the use of ATDs that are median-male based. The injury assessment reference values (IARVs) for the neck, which were developed for relating the loads measured by ATDs to the potential for injury in humans, are based on a limited set of male human volunteer and cadaveric data (Mertz et al., 2003; Foster et al., 1977). These data have then been scaled using size (neck circumference) and tissue properties (calcaneal tendon strength) to provide IARVs for the 5th percentile female and 95th percentile male Hybrid III dummies. In the case of children, porcine models have been used to generate injury data, although the translation between animal and human data is outside the scope of the current study (Mertz et al., 2003).

There are considerable field data showing that female, elderly, and obese individuals are at greater risk than 50th percentile adult males of serious and fatal injuries across all body regions in similar severity collisions (Evans and Gerrish, 2001; Bédard et al., 2002; Hill and Boyle, 2006; Zhu et al., 2006; Bose, 2011; Rupp et al., 2013; Carter et al., 2014). Using data from the National Automotive Sampling System's Crashworthiness Data System (NASS-CDS), Bose et al. (2011) found that the odds of a beltrestrained female driver sustaining severe injuries were $47 \%$ higher than those for a belt-restrained male driver involved in a comparable crash. Hill and Boyle (2006) found that females and older occupants (75+ year olds) were at a significantly higher risk of a severe injury in crashes recorded in the United States General Estimate System (GES). Evans and Gerrish (2001) used the Fatality Analysis Reporting System (FARS) database to compare the risk of fatal injury in two-car crashes where the sex of one driver was male and the other was female and found the fatality risk to be $22 \%$ greater for female drivers. Bédard et al. (2002) also used the FARS database to examine fatality risk in single vehicle collisions with fixed objects and found the odds ratio of fatal injury increases with age $(\mathrm{OR}=4.98$ for $80+$ year olds) and female sex (OR = 1.54). Rupp et al. (2013) found that obese subjects were at an increased risk of AIS 3+ spine injuries. While other vehicle- and crash-related factors that co-vary with sex, age, and occupant obesity may explain some of these findings, biomechanical factors related to these variables are plausible explanations for some proportion of the observed effects.

A similar pattern of increased injury risk for female, elderly, and obese individuals is also observed specifically for head and neck injuries. Carter et al. (2014) found that older individuals have a greater risk of severe spine injuries in frontal and rollover crashes. Furthermore, females are at about double the risk of males for whiplash injuries in low speed rear-end collisions (Krafft et al., 2003; Jakobsson et al., 2004; Linder and Svensson, 2019). Moreover, active head restraints have been shown to be more effective for men than women (Kullgren et al., 2013).

Sex and anthropometry also affect the kinematics of individuals in collisions. In volunteer studies, females exhibit higher magnitude head accelerations in both frontal and rear-end collisions (Siegmund et al., 1997; van den Kroonenberg et al., 1998). In rear impacts, females also exhibit greater forward rebound and larger intersegmental motion between adjacent vertebrae in the cervical spine (Ono et al., 2006). Reed et al. (2012) studied obese and non-obese subjects and showed that excess slack was introduced in the belt system in obese subjects. In post-mortem human subjects (PMHSs), obese subjects experienced greater excursion and tended to pitch forward less than the non-obese subjects in $48 \mathrm{~km} / \mathrm{h}$ frontal collisions (Kent et al., 2010). Computational models have also predicted higher neck displacements for females than for males in low-speed rearend collisions (Viano, 2003) and poor concordance has been observed between the Global Human Body Models Consortium (GHBMC) finite element model and obese PMHS tests (Gepner et al., 2018).

Sex differences in external neck morphology and anatomical differences in the cervical spine have also been established. The vertebral anatomy, curvature, head mass, neck strength, neck muscle morphometry, and neck muscle activation patterns have all been shown to differ between males and females (Brault et al., 1998; Kamibayashi and Richmond, 1998; Matsumoto et al., 1998; Siegmund et al., 2003a; Klinich et al., 2004; Stemper et al., 2008; Vasavada et al., 2008; Sato et al., 2017).

The above review suggests that injury prevention technologies (e.g., restraint systems, airbags, and head restraints) have been primarily designed using representations and scalings of midsized male occupants, and that sex, age, and anthropometry potentially affect neck injury risk, head and neck kinematics, and ultimately neck injury mechanics in automotive collisions. While the biomechanics of these relationships and the degree to which sex, age, and anthropometry explain these relationships remains unclear, an important first step in addressing this potential inequity in injury prevention is to understand the diversity-or lack of diversity - in the baseline biomechanical data that inform our understanding of occupant kinematics and tolerances, and motivate our designs of ATDs and safety 
TABLE 1 | Study eligibility criteria.

Inclusion criteria

- Test volunteer or cadaver subjects with or without helmets

- Measure primary data on time history accelerations or displacements of both the human head and base of the neck or upper thorax (C6-T4 range)

- Involve accelerating the head by means of inertial loading or direct head or body impact
Exclusion criteria

- Solely use subjects who have undergone spinal surgery, have apparent or induced injuries, have been otherwise altered, or exhibit extreme spine pathologies

- Involve modifying the kinematics of the head and neck through additional impacts (airbags, steering wheels, head restraints) or other factors

- Poor methodology or insufficient detail to assess the quality of the methods used to obtain and modify data (requires the agreement of two reviewers) technologies. Therefore, our objective here is to quantify the distributions of sex, age, height, weight, and BMI for volunteer and PMHS tests that make up the available neck biomechanical data and to compare the distributions of these parameters to reference data drawn from the neck-injured, fatally-injured, and general populations.

\section{METHODS}

\section{Literature Search}

A systematic search was performed for published studies that contained kinematic data for the head and torso in response to inertial loading and direct head and body impacts, and from which the neck response could be estimated. Five databases (PubMed, Web of Science Core Collection, Compendex Engineering Village, SportDiscus, and SAE Mobilus) were searched in June/July 2020 with no restrictions on year or language of publication. The search terms reflected the eligibility criteria, including keywords targeting human subjects and cadavers, head, neck and torso kinematics, and impact loading. Studies extracted from relevant review articles were also added to the results of these searches.

A sample Web of Science search is as follows:

\#1 TS = (Volunteer ${ }^{\star}$ OR "In Vivo" OR Cadaver ${ }^{\star}$ OR “Ex Vivo" OR “Post mortem” OR PMHS).

\#2 TS = (head).

\#3 TS $=($ sled OR "crash test*" OR impact*)

\#4 TS $=$ (acceleration ${ }^{\star}$ OR displacement ${ }^{\star}$ )

\#4 AND \#3 AND \#2 AND \#1.

Studies from the search results were first compiled and deduplicated using Legacy RefWorks (ProQuest, Ann Arbor, MI). One author screened the titles and abstracts based on preset criteria (Table 1) and then performed a full-text review on the relevant subset to identify eligible studies containing the desired data using Covidence (Melbourne, Australia). A second author reviewed studies whose inclusion/exclusion was ambiguous. For eligible studies, we then determined if the kinematic data were available in the publication, appendix, supplementary material, by contacting the authors, or searching biomechanics databases (e.g., National Biodynamics Laboratory, Air Force Biodynamic, and NHTSA Biomechanics databases). We then extracted the sex, age, height, weight, and BMI for all volunteers and cadavers from each test within the included studies. These characteristics were compared to reference data for automotive neck injuries (NASS-CDS), automotive fatalities (FARS), and the general population (US Census Bureau, USCB).

\section{Reference Data}

From the NASS-CDS dataset that had AIS codes (1993-2015), we extracted all cases with cervical spine injuries (Region 6, Structures 02, 50 and 59 based on the 1998 Abbreviated Injury Scale) for light vehicles (Body types 1-49) and all types of crashes. For each unique individual $(n=25,889)$, we extracted the maximum Abbreviated Injury Scale (AIS) score for their cervical spine injury, as well as their sex, age, height, weight, and BMI when present. Individuals were removed from the dataset if their sex was unknown $(n=9)$ or if their age, height, and weight were all unreported $(n=4)$. Individuals with $\mathrm{BMI}>76$ were removed, as there were continuous data up to a BMI of 76, after which the values doubled and were assumed to be errors $(n=17)$. The data were then grouped into three datasets based on injury severity: AIS1+, AIS2+, and AIS3+ injuries. Injuries of unknown severity (coded as AIS 7 in NASS) were included in the AIS1+ group but removed from AIS2+ and AIS3+ groups. Pregnant females were included in the age and height datasets but excluded from the weight and BMI datasets.

From the FARS data, we queried the Fatality and Injury Reporting System Tool (FIRST) to extract the sex and age of all drivers and occupants who died in motor vehicle crashes in the full date range of the available data (2005-2019). The FARS database did not contain height or weight data. The FARS data included deaths from all types of injuries, not just cervical spine injuries.

From the census data, we extracted the estimated 2017 United States population for females and males at each year of age between 0 and 100 years (US Census Bureau, 2021). All individuals over 100 years old were pooled into the 100 -years category. To estimate the height and weight distributions of the general population, we first fit a lognormal distribution to the percentile distribution data $(5,10,15,25,50,75,85,90$, and 95th percentiles) of the height and weight data for each sex and year of age (Fryar et al., 2021) and then calculated a weighted sum of these distributions based on the number of people in each age group. Separate height and weight distributions were used for each year from 2 to 19 years and for each decade thereafter (e.g., 20-29 years, 30-39 years, ... , 70-79 years, $80+$ years). No information on the correlation between height and weight was available, therefore BMI for the general population was not computed. 


\section{Data Distributions}

Histograms for age, height, weight and BMI were created for the number of volunteer tests, PMHS tests, AIS1+ injured individuals, AIS2+ injured individuals, AIS3+ injured individuals, fatalities, and people in the general population. We focused our analysis on the number of volunteer and PMHS tests rather than the number of volunteers or cadavers because each test yielded a unique set of data. As a result, a volunteer or cadaver could appear multiple times in the histograms. The histograms pooled both sexes and used bin widths of 1 year, $1 \mathrm{~cm}, 1 \mathrm{~kg}$, and $1 \mathrm{~kg} / \mathrm{m}^{2}$ for age, height, weight, and BMI, respectively. For the AIS data, the bin widths for height were set to $2.54 \mathrm{~cm}$ (1 inch) and $2.258 \mathrm{~kg}$ (5 pounds) for weight. Separate density distributions for each sex were then generated using kernel density estimates (geom_density function in R). For a dataset with $\mathrm{N}$ observations, this function yields the sum of $i=1$ to $\mathrm{N}$ normal distributions, where the mean of the $i$ th distribution equals the value of the $i$ th observation and the standard deviation for all $\mathrm{N}$ distributions equals the optimum bandwidth (Silverman, 1986). The optimum bandwidth for each dataset was calculated using Eq. 1 (Silverman, 1986, pg 48), and then all bandwidths for a given parameter (age, height, weight, or BMI) were averaged to select a common bandwidth for all distributions of the same parameter. The average bandwidths for each parameter were as follows: age 2.90 years, height $1.40 \mathrm{~cm}$, weight $2.95 \mathrm{~kg}$, and BMI $1.01 \mathrm{~kg} / \mathrm{m}^{2}$. The bandwidth for height was doubled from 0.70 to $1.40 \mathrm{~cm}$ as the average optimum bandwidth created unrealistic peaks in the data with $1-\mathrm{cm}$ bin widths.

$$
\text { Optimum bandwidth }=0.9 \min (\mathrm{SD}, \mathrm{IQR} / 1.34) \times \mathrm{N}^{-0.2}
$$

where $\mathrm{SD}=$ standard deviation of the dataset, and IQR = interquartile range of the dataset.

The histograms related to all distributions for a single parameter were plotted at the same scale, i.e., the areas of all related histograms are equal to one. The relative areas under the female and male distributions reflect their relative proportions of the population. The areas for the female and male distributions were doubled, i.e., their sum is double the area of the histogram, to improve their visibility relative to the histograms. The medians for the male and female data were computed using all of the data within a dataset. For the general population, the medians for the height and weight of adults ( $\geq 16$ years) were also calculated. Dispersion within each of the datasets was quantified using the interquartile range (IQR).

\section{RESULTS}

Our search yielded 2,249 unique studies, of which 417 studies were relevant to our objectives, 91 of the 417 relevant studies measured the kinematic variables we sought, and 63 of these studies presented or otherwise allowed access to their data (Figure 1). The 63 studies contained 999 unique volunteers exposed to 5,229 tests and 110 unique PMHSs exposed to 202 tests (Ewing et al., 1969; Ewing and Thomas, 1972; Ewing et al., 1975; Ewing et al., 1977, Ewing et al., 1978; Kallieris et al., 1987; Buhrman and Perry, 1994; Margulies et al., 1998; Morris and Popper, 1999; Ono et al., 1999; Yoganandan and Pintar, 2000; Davidsson et al., 2001; Meijer et al., 2001; Fugger et al., 2002; Petitjean et al., 2002; Vezin et al., 2002; Deng and Wang, 2003; Perry et al., 2003; Siegmund et al., 2003a; Siegmund et al., 2003b; Vezin and Verriest, 2003; Doczy et al., 2004; Siegmund et al., 2004; Blouin et al., 2006; Rouhana et al., 2006; Wiechel and Bolte, 2006; Ejima et al., 2007; Pintar et al., 2007; Ejima et al., 2008; Siegmund et al., 2008; Arbogast et al., 2009; Funk et al., 2009; Lopez-Valdes et al., 2009; Siegmund and Blouin, 2009; White et al., 2009; Lopez-Valdes et al., 2010; Pintar et al., 2010; Funk et al., 2011; Sundararajan et al., 2011; Arbogast et al., 2012; Ejima et al., 2012; Stammen et al., 2012; Symeonidis et al., 2012; Forman et al., 2013; Mathews et al., 2013; Poulard et al., 2013; van Rooij et al., 2013; Crandall et al., 2014; Gutsche et al., 2014; Lessley et al., 2014; Lopez-Valdes et al., 2014; Seacrist et al., 2014; Shaw et al., 2014; Acosta et al., 2016; López-Valdés et al., 2016; Pietsch et al., 2016; Albert, Beeman and Kemper, 2018; Holt et al., 2018; Humm et al., 2018; Petit et al., 2019; Stark et al., 2019; Zaseck et al., 2019; Holt et al., 2020). About $66 \%$ of the volunteer tests and $84 \%$ of the PMHS tests were conducted with males (Table 2, also visible in Figures 2-5). Both values were higher than the proportion of males in the United States population (49\%) and in the AIS1+, AIS12+, and AIS13+ neck injury groups $(48,60$, and $63 \%$, respectively), but landed on either side of the proportion of males seen in United States automotive fatalities (70\%).

Of the four variables we examined, age showed the largest differences between datasets (Figure 2). The median ages for the PMHS tests were higher than all of the reference datasets, ranging from as little as 26 years older than the FARS data (males) up to 40 years older than the AIS1+ data (females). The youngest female and male PMHSs tested were 46 and 22 years old, respectively. The median ages for the volunteer tests, on the other hand, were lower than all of the reference datasets by a maximum of 14 years relative to the FARS data (females). In addition to differences in the medians, the age-related dispersions (IQRs) of both the volunteer tests and the PMHS tests were less than all of the reference datasets (Table 2). Dispersion was smallest for the female volunteer tests (7 years) and largest for the female fatalities and female population data ( 38 years). There were no volunteer or PMHS tests for female children or adolescents ( $\leq 17$ years old) and the oldest female and male volunteer test subjects were 63 and 65 years old, respectively.

The median height of the female PMHS tests was only $2 \mathrm{~cm}$ shorter than the median female in the United States population, but 6-7 cm shorter than females with neck injuries (Figure 3). In contrast, the median height of the female volunteer tests was 3-4 cm taller than the females with neck injuries. For males, the median height for the volunteer tests was the same as the median for the adult United States population (Figure 3), but 3-4 cm shorter than the median heights for the PMHS tests and the neck injured populations. The dispersions in height for the female volunteer data and for both the male and female PMHS data were less than the dispersion for the neck-injured population and the general population. 


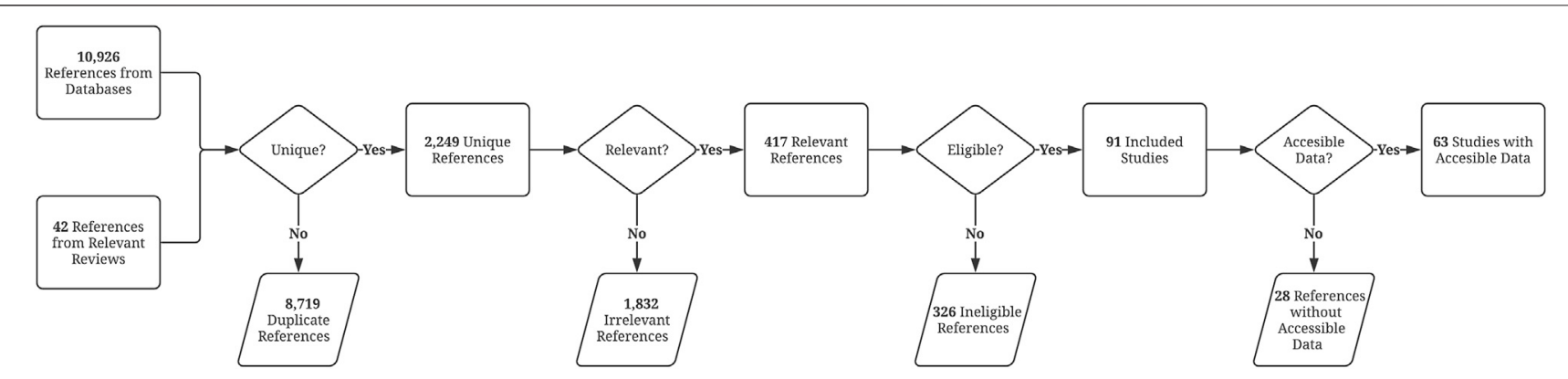

FIGURE 1 | Flowchart showing the number of studies at each stage of the selection process.

TABLE 2 | Sample size (n), median, and interquartile range (IQR) of the age, height, weight, and BMI data for the volunteer tests, PMHS tests, AIS1+, AIS2+, and AIS3+ from the NASS data, FARS data, and the United States population.

\begin{tabular}{|c|c|c|c|c|c|c|c|c|c|c|c|c|c|}
\hline & & \multicolumn{3}{|c|}{ Age (years) } & \multicolumn{3}{|c|}{ Height (cm) } & \multicolumn{3}{|c|}{ Weight (kg) } & \multicolumn{3}{|c|}{ BMI $\left(\mathbf{k g} / \mathbf{m}^{2}\right)$} \\
\hline & & $\mathbf{n}$ & Median & IQR & $\mathbf{n}$ & Median & IQR & $\mathbf{n}$ & Median & IQR & $\mathbf{n}$ & Median & IQR \\
\hline \multirow[t]{3}{*}{ Volunteers } & Total & 5,296 & 26 & 11 & 5,296 & 172 & 10 & 5,296 & 69 & 14 & 5,296 & 23 & 3 \\
\hline & Male & 3,544 & 26 & 11 & 3,544 & 174 & 10 & 3,544 & 75 & 13 & 3,544 & 24 & 3 \\
\hline & Female & 1752 & 27 & 7 & 1752 & 168 & 6 & 1752 & 65 & 10 & 1752 & 23 & 2 \\
\hline \multirow[t]{3}{*}{ PMHS } & Total & 195 & 65 & 17 & 196 & 176 & 11 & 196 & 75 & 17 & 196 & 24 & 5 \\
\hline & Male & 166 & 65 & 15 & 166 & 177 & 6 & 166 & 77 & 18 & 166 & 25 & 4 \\
\hline & Female & 29 & 72 & 20 & 30 & 157 & 7 & 30 & 54 & 25 & 30 & 22 & 9 \\
\hline \multirow[t]{3}{*}{ AlS1+ } & Total & 25,859 & 31 & 24 & 21,962 & 170 & 15 & 22,183 & 73 & 25 & 21,594 & 25 & 7 \\
\hline & Male & 12,458 & 31 & 23 & 10,476 & 178 & 10 & 10,708 & 82 & 21 & 10,411 & 26 & 6 \\
\hline & Female & 13,401 & 32 & 25 & 11,486 & 165 & 10 & 11,475 & 64 & 20 & 11,183 & 24 & 8 \\
\hline \multirow[t]{3}{*}{ AlS2+ } & Total & 4,410 & 35 & 29 & 3,810 & 173 & 15 & 3,866 & 76 & 24 & 3,769 & 25 & 7 \\
\hline & Male & 2,658 & 34 & 26 & 2,270 & 178 & 10 & 2,318 & 82 & 19 & 2,257 & 26 & 6 \\
\hline & Female & 1752 & 38 & 35 & 1,540 & 165 & 12 & 1,548 & 66 & 22 & 1,512 & 24 & 8 \\
\hline \multirow[t]{3}{*}{ Als3+ } & Total & 1985 & 36 & 30 & 1,680 & 173 & 15 & 1,696 & 77 & 24 & 1,654 & 25 & 7 \\
\hline & Male & 1,243 & 35 & 26 & 1,036 & 178 & 10 & 1,054 & 82 & 19 & 1,028 & 26 & 6 \\
\hline & Female & 742 & 38 & 36 & 644 & 164 & 13 & 642 & 65 & 20 & 626 & 24 & 8 \\
\hline \multirow[t]{3}{*}{ FARS } & Total & 455,886 & 39 & 33 & - & - & - & - & - & - & - & - & - \\
\hline & Male & 320,917 & 38 & 31 & - & - & - & - & - & - & - & - & - \\
\hline & Female & 134,969 & 41 & 38 & - & - & - & - & - & - & - & - & - \\
\hline \multirow[t]{3}{*}{ United States Pop } & Total & $324,982,000$ & 38 & 38 & $321,006,000$ & 165 & 17 & $321,013,000$ & 75 & 33 & - & - & - \\
\hline & Male & $160,044,000$ & 36 & 37 & $158,034,000$ & 173 & 12 & $158,035,000$ & 82 & 33 & - & - & - \\
\hline & Female & $164,938,000$ & 39 & 38 & $162,972,000$ & 159 & 11 & $162,978,000$ & 70 & 30 & - & - & - \\
\hline
\end{tabular}

The weight data exhibited a similar pattern to the height data. The median weight of the female PMHS tests was $10-12 \mathrm{~kg}$ less than the females in the neck-injured groups and $16 \mathrm{~kg}$ less than females in the general population (Figure 4). For males, the median weights for the volunteer and PMHS tests were $5-7 \mathrm{~kg}$ less than both the neck-injured and general populations. Dispersion in the weight of the female volunteer tests was about half of the neck injured population and a third of the general population, whereas the dispersion in the PMHS data fell within the range between the neck-injured and general populations. For males, the dispersion in the volunteer tests was also about one third of the general population, but the PMHS and neck-injured populations were similar to one another.

Volunteers and PMHSs had slightly lower median BMIs than seen in the neck-injured populations (Figure 5). The median BMIs of the male volunteers and the female PMHSs differed the most, by $2 \mathrm{~kg} / \mathrm{m}^{2}$, from the neck-injury populations. Dispersion in the volunteer BMI's was one half of the neck-injured population for females and one quarter of the neck-injured population in males.

\section{DISCUSSION}

Our goal was to quantify the sex, age, and anthropometry of the volunteers and cadavers that comprise the available kinematic data for the human neck and to compare the distributions of these variables to those of the neck-injured, fatally-injured, and general populations. Overall, we found large differences in the sex and age distributions between the biomechanical data and the reference populations, and smaller, primarily female-specific, differences in the height, weight, and BMI distributions between the biomechanical data and reference populations. These findings point to an underlying lack of diversity in the biomechanical data 
A

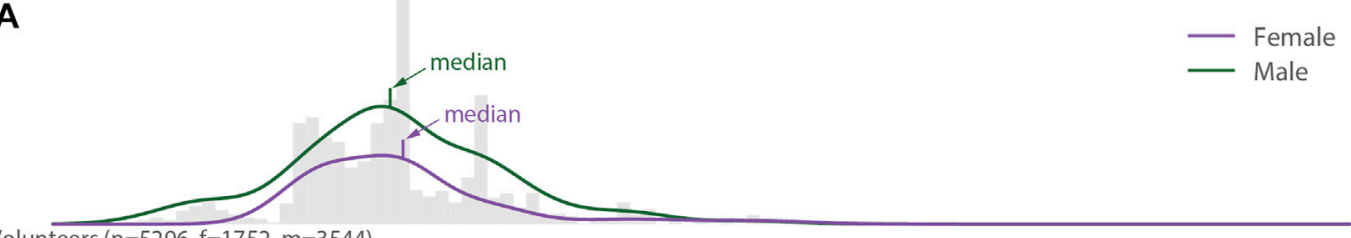

Volunteers $(n=5296, f=1752, m=3544)$

B

PMHS $(\mathrm{n}=195, \mathrm{f}=29, \mathrm{~m}=166)$

C

NASS AIS1+ (n=25,859, $f=13,401, m=12,458)$

D

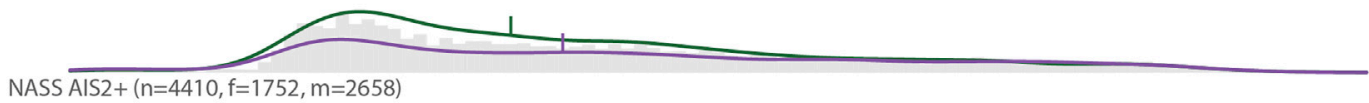

NASS AIS2 $+(n=4410, f=1752, m=2658)$

E

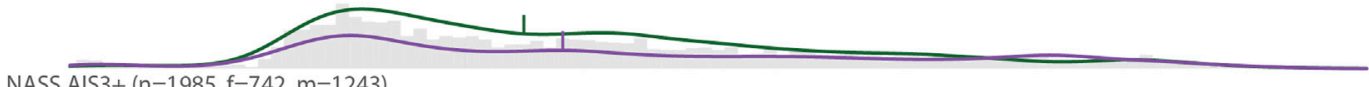

NASS AIS3+ ( $n=1985, f=742, m=1243)$

$\mathbf{F}$

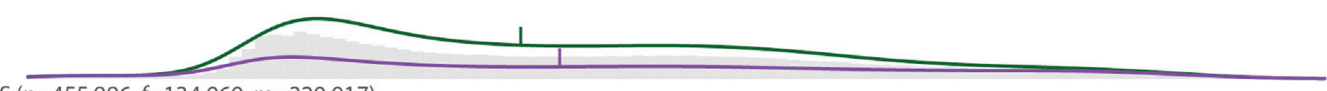

FARS $(\mathrm{n}=455,886, \mathrm{f}=134,969, \mathrm{~m}=320,917)$

G

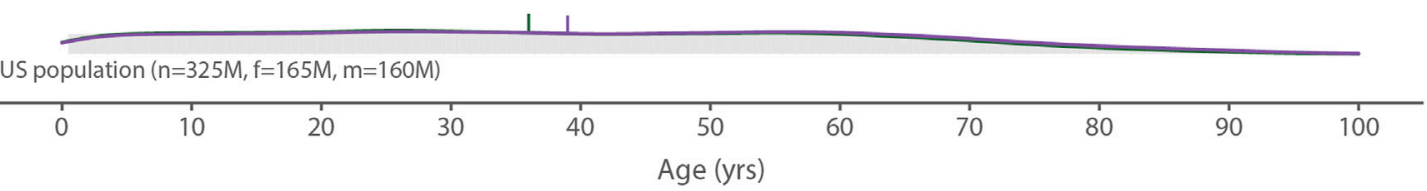

FIGURE 2 Distribution of all age data (gray histograms), females (purple lines), and males (green lines) for (A) the volunteer tests, (B) the PMHS tests, (C) the NASS AIS1+ data, (D) the NASS AIS2+ data, (E) the NASS AIS3+ data, (F) the FARS data, and (G) the United States population. 


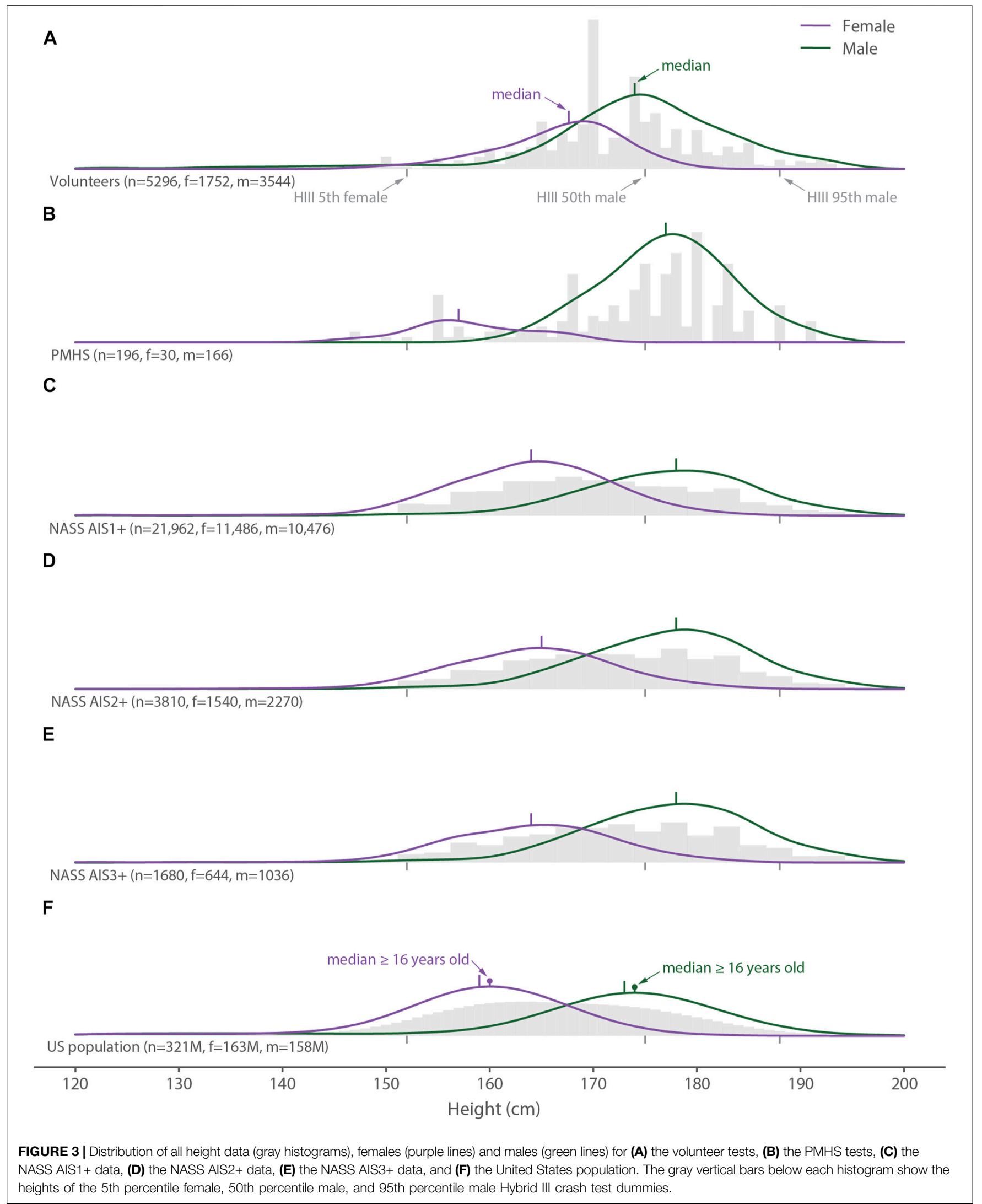




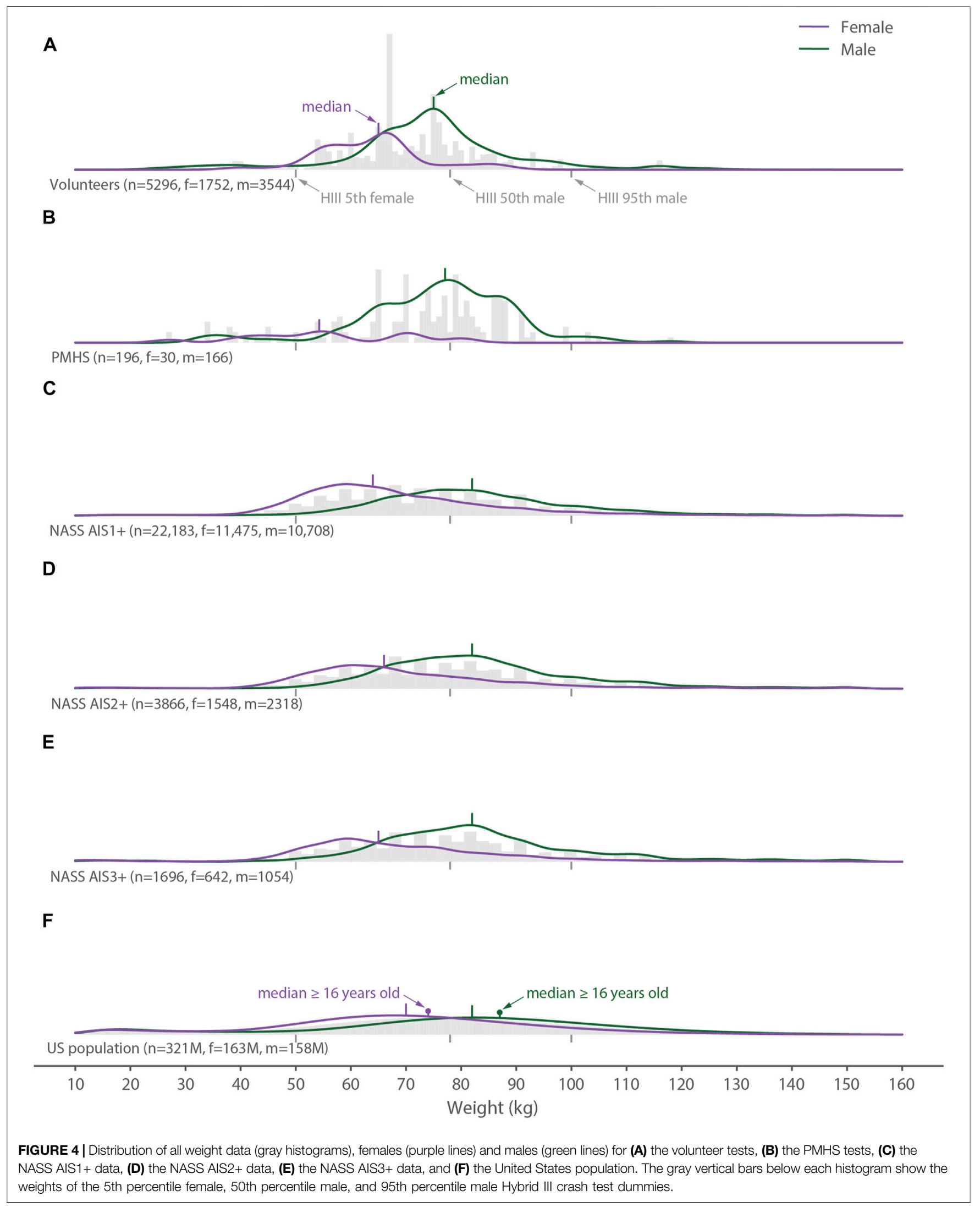




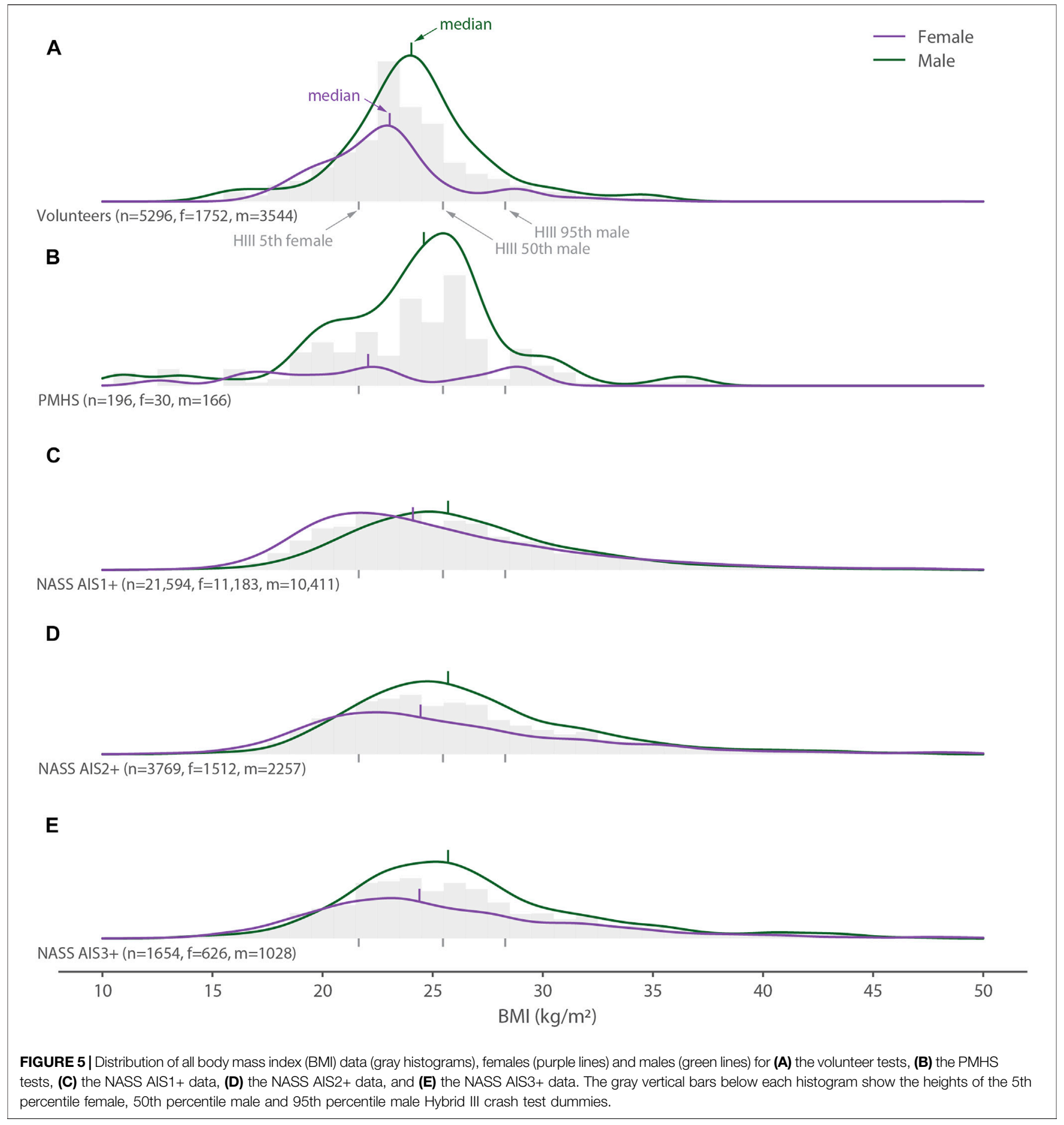

being used to understand and ultimately prevent collision-related neck injuries.

The most obvious difference between the biomechanical and reference datasets is between males and females. There were twice as many male volunteer tests as female volunteer tests (67\% male vs. $33 \%$ female) and over five times as many male PMHS tests as female PMHS tests ( 85 vs. $15 \%$ ). In contrast, there were fewer males than females ( 48 vs. $52 \%$ ) with neck injuries across the entire range of severities (i.e., AIS1+) and 1.67 times more males than females (63 vs. $37 \%$ ) when only serious and more severe neck injuries (AIS3+) were considered. Although males were $\sim 2.4$ times more likely than females (70 vs. $30 \%$ ) to die in a road crash based on FARS data, this database captures deaths from non-neck-related trauma and is therefore a poorer reference for the appropriate diversity needed in the neck biomechanical data. Based on these findings, more biomechanical data are needed for 
females throughout the neck injury spectrum-from whiplash injury to neck fractures-although the optimum sex distribution of volunteers and PMHSs may vary for different neck injuries. For instance, volunteer tests may be more relevant for studying AIS1 injuries and therefore a bias toward more female than male subjects should be considered to better reflect the AIS1 injured population; whereas cadaver tests may be more relevant for studying severe neck injuries and therefore a bias toward more male than female cadavers-albeit less bias than currently exists-could be considered to reflect the AIS3+ injured population. More generally, our findings suggest that the applicability of biomechanical research could be improved if researchers queried the available field data for sex and anthropometry distributions relevant to the injury of interest and then enrolled volunteers and/or cadavers to match.

The age differences we observed between the biomechanical and reference datasets were primarily in the PMHS data. This finding is not surprising given that $75 \%$ of deaths in males and $85 \%$ of deaths in females occur at over 65 years of age (Shumanty, 2018), making old cadavers more readily available to researchers. Nevertheless, there are established age-related changes in tissue morphology and failure response that potentially confound comparisons between the volunteer and PMHS data (Yukawa et al., 2012; Yoganandan et al., 2018). These differences create problems when combining the geometric, kinematic, and neuromuscular data of young volunteers with the failure data of old cadavers, particularly when creating human body models, developing injury assessment reference values, or designing safety interventions. For example, the neck IARVs developed for correlating injury tolerances with the Hybrid III are scaled using tissue properties which are likely to be biased by the older age of cadaveric specimens (Mertz et al., 2003). Another key age-related difference is the complete absence of volunteer and cadaveric data for female children and adolescents. While injury rates to this sub-population are relatively low, the societal costs of injury to children are high and therefore biomechanical data from both sexes are needed to first understand if differences exist and then how to accommodate for them if present.

Though not a goal of the study, we observed that the neckinjured population was taller than the general population. The reasons for this difference cannot be discerned directly from our data, but possible explanations include a longer distance between the inertial mass of the head and the fulcrum created by the shoulder belt crossing the chest and shoulder during frontal crashes, a greater chance of head contact and neck loading during other types of impacts, and different interactions with airbags. Further work is needed to better understand this pattern and its possible importance when recruiting volunteers and selecting cadavers for studying neck injury. The height of female cadavers was even shorter than the general population and therefore matched the distribution of neck-injured females even more poorly. The heights of the three common Hybrid III dummies (5th female, 50th male, and 95th male; shown in Figure 3) appear to cover the range of injured individuals but result in many of the females landing in the gap between the 5th female and the 50th male dummy. Moreover, a median height for the neck-injured male population that is $\sim 5 \mathrm{~cm}$ taller than the 50th-percentile male dummy, which is the most commonly used dummy for vehicle standards testing, may not be optimizing vehicle safety for taller male occupants.

In contrast to height, the weight distributions of neckinjured individuals and both the volunteer and PMHS data are lower than for the general population. The weight of female PMHSs is low compared to the other distributions, possibly signifying attempts by researchers to generate data related to the 5th-percentile female dummy. Although the BMI distribution of the general population was not determined because the covariance of height and weight was not available, the volunteer and PMHS test data was below the median levels for the neck-injured populations.

To interpret our findings, one should consider the different kinds of biomechanical data generated from volunteer and PMHS tests. Volunteers are exposed to lower, often sub-injurious conditions and the acquired data consist of kinematics from external sensors or motion tracking, intervertebral kinematics acquired via fluoroscopy, muscle activation data from surface or in-dwelling electromyography, kinetics computed via inverse dynamics, and potentially subjective or objective clinical data (including pre- and post-test imaging). Volunteer data can yield information related to realistic initial postures, neuromuscular responses, and potential pain measures. Cadavers, on the other hand, are often exposed to injurious loading conditions. These are the only human subjects that can be exposed to injurious or potentially injurious loads. The acquired data from PMHS tests consist of kinematic and kinetic data from external/embedded sensors or motion tracking, intervertebral data from high-speed $\mathrm{x}$-ray, pre- and post-test imaging, and post-test dissection to identify injuries. Cadaver data can yield information regarding the tolerance to injuries detected via imaging, visible inspection and/or dissection, or post-impact mechanical testing. Given these differing conditions, outcomes, and ethical considerations, volunteer data may be more relevant to less severe neck injuries whereas PMHS data may be more relevant to more severe neck injuries.

Although our findings showed differences in the sex, age, and anthropometry of the biomechanical and reference populations, our analysis did not reveal whether the presence or scale of these differences was important. Previously documented morphological (Siegmund et al., 1997; Kamibayashi and Richmond, 1998; Matsumoto et al., 1998; Klinich et al., 2004; Stemper et al., 2008; Vasavada et al., 2008; Sato et al., 2017) and physiological differences (Ono et al., 2006; Vasavada et al., 2008) between male and female necks combined with the different risks for spine injuries in males and females in frontal and rollover crashes (Carter et al., 2014) suggests that some sex or sex-related variables could be responsible, but our understanding of the complex relationships amongst the many potential variables remains incomplete. For instance, sex, height, and weight are all interrelated, and even "normalized" metrics like BMI vary with sex and other variables (Heymsfield et al., 2014), and one variable could act as a surrogate for another in an exploratory correlational analysis. More mechanistic approaches, where individual variables or a small number of variables are systematically explored, are needed to determine which 
variables are most important for a specific injury. Other factors, such as hormones, health, prior injury, disease state, and other variables further complicate our understanding of neck injury biomechanics.

We chose to tabulate volunteer and PMHS tests rather than the individual volunteers and cadavers. While we recognize that multiple tests from a single volunteer/cadaver do not generate independent data, many of the tests were not identical and therefore generated different, though not wholly independent data. From this perspective, our analysis provides an optimistic view of the amount of biomechanical data available for the human neck, and yet it still shows that there are large gaps in the overlap between the biomechanical data, the neck-injured population and the general population. A parallel set of figures reporting the data for individual volunteers and cadavers showed similar results (see the Supplementary Materials). In these alternate figures male subjects outnumber female subjects, the biases toward young volunteers and old cadavers remain, and the female anthropometry data remained shifted toward the 5thpercentile female.

The median and distribution of human anthropometry varies temporally and across the world's regions (Lee and Bro, 2008), and therefore using a reference population from a single year and country provides a perspective that may not be relevant to another year or country. We used recent measures of the United States population as a reference to directly compare with the United States injury datasets, however any population of interest to future researchers could be compared with the volunteer and PMHS figures. Additionally, safety systems in automobiles have changed considerably since 1993 and may confound our injury curves. To explore the effect of the differing time periods on the injury data, we split the NASS dataset into two groups: data preceding (1993-2004) and data overlapping (2005-2015) the available FARS data period. The greatest differences between the two groups were for age and weight. If we were to plot only the data from the later group, then compared to the overall data shown in the figures the mean age would increase 2.0 years for AIS1+, 1.1 years for AIS2+ and 0.7 years for AIS3+, whereas the average weight would increase $2.2 \mathrm{~kg}$ for AIS1+ and AIS2+ and $2.0 \mathrm{~kg}$ for AIS3+. Thus, at maximum, the age and weight histograms presented in the figures would shift about one bin width to the right, but would not change our overall findings. Another limitation of our work is that we did not separate either the biomechanical data or the neck-injured population by loading direction, crash type or injury type. Nevertheless, we recommend that researchers planning to conduct future volunteer and cadaver tests consider these specific factors when they specify or set up recruitment plans for the sex, age, and anthropometry distributions of their volunteers and cadavers.

\section{REFERENCES}

Acosta, S. M., Ash, J., Lessley, D., Shaw, C. G., Heltzel, S., Crandall, J., et al. (2016). Comparison of Whole Body Response in Oblique and Full Frontal Sled Tests,

\section{CONCLUSION}

We found large differences in the distributions of sex and age between the populations used to generate biomechanical data for the human neck and the neck-injured populations. Smaller differences were noted in the height, weight, and BMI distributions between these populations. Overall, our findings indicate that more female biomechanical data are needed, especially for females of average height and weight. Our findings also show that there is minimal biomechanical data for older volunteers, young cadavers, and volunteers of both sexes with high BMIs. More generally, we encourage researchers to consider the diversity of the population being injured when enrolling volunteers and cadavers for their biomechanical studies.

\section{AUTHOR CONTRIBUTIONS}

GB developed the study protocol with the assistance of PC and conducted the systematic literature search. PC reviewed papers where the methodology or relevance was ambiguous. GB collected and compiled the biomechanical subject data from papers, databases, or directly from the authors. GS queried the NASS-CDS database and calculated the United States Population distributions. GB queried the FARS data and synthesized each dataset into distributions. PC drafted the introduction, GB and GS drafted the methods and results, and GS drafted the discussion. All authors edited and approved the final article.

\section{FUNDING}

We gratefully acknowledge the Natural Sciences and Engineering Research Council of Canada for funding this project with a Discovery Grant (\# RGPIN-2017-06013) and the Work Learn International Undergraduate Research Award at the University of British Columbia that supported author GB's work on this project.

\section{ACKNOWLEDGMENTS}

The authors would like to acknowledge Sarah Parker for her valuable assistance and expertise in developing the literature search protocol.

\section{SUPPLEMENTARY MATERIAL}

The Supplementary Material for this article can be found online at: https://www.frontiersin.org/articles/10.3389/fbioe.2021.684217/ full\#supplementary-material

2016 IRCOBI Conference Proceedings (Malaga, Spain: International Research Council on the Biomechanics of Injury), 15.

Albert, D. L., Beeman, S. M., and Kemper, A. R. (2018). Occupant Kinematics of the Hybrid III, THOR-M, and Postmortem Human Surrogates under Various Restraint Conditions in Full-Scale Frontal 
Sled Tests. Traffic Inj. Prev. 19 (Suppl. 1), S50-S58. doi:10.1080/ 15389588.2017.1405390

Arbogast, K. B., Mathews, E. A., Seacrist, T., Maltese, M. R., Hammond, R., Balasubramanian, S., et al. (2012). The Effect of Pretensioning and Age on Torso Rollout in Restrained Human Volunteers in Far-Side Lateral and Oblique Loading. Stapp Car Crash J. 56, 443-467. doi:10.4271/2012-22-0012

Arbogast, K. B., Balasubramanian, S., Seacrist, T., Maltese, M. R., Garcia-Espana, J. F., Hopely, T., Constans, E., Lopez-Valdes, F. J., Kent, R. W., Tanji, H., and Higuchi, K. (2009). "Comparison of Kinematic Responses of the Head and Spine for Children and Adults in Low-Speed Frontal Sled Tests," in 53rd Stapp Car Crash Conference, November 2-4, 2009, Savannah, GA, 2009-22-0012. doi:10.4271/2009-22-0012

Bédard, M., Guyatt, G. H., Stones, M. J., and Hirdes, J. P. (2002). The Independent Contribution of Driver, Crash, and Vehicle Characteristics to Driver Fatalities. Accid. Anal. Prev. 34 (6), 717-727. doi:10.1016/S0001-4575(01)00072-0

Blouin, J.-S., Inglis, J. T., and Siegmund, G. P. (2006). Auditory Startle Alters the Response of Human Subjects Exposed to a Single Whiplash-like Perturbation. Spine 31 (2), 146-154. doi:10.1097/01.brs.0000195157.75056.df

Bose, D., Segui-Gomez, ScD, M., and Crandall, J. R. (2011). Vulnerability of Female Drivers Involved in Motor Vehicle Crashes: an Analysis of US Population at Risk. Am. J. Public Health 101 (12), 2368-2373. doi:10.2105/AJPH.2011.300275

Brault, J. R., Wheeler, J. B., Siegmund, G. P., and Brault, E. J. (1998). Clinical Response of Human Subjects to Rear-End Automobile Collisions. Arch. Phys. Med. Rehabil. 79, 72-80. doi:10.1016/s0003-9993(98)90212-х

Buhrman, J. R., and Perry, C. E. (1994). Human and Manikin Head/neck Response to $+\mathrm{Gz}$ Acceleration when Encumbered by Helmets of Various Weights. Aviat Space Environ. Med. 65 (65), 1086-1090.

Carter, P. M., Flannagan, C. A. C., Reed, M. P., Cunningham, R. M., and Rupp, J. D. (2014). Comparing the Effects of Age, BMI and Gender on Severe Injury (AIS 3+) in Motor-Vehicle Crashes. Accid. Anal. Prev. 72, 146-160. doi:10.1016/ j.aap.2014.05.024

Crandall, J., Lessley, D., Shaw, G., and Ash, J. (2014). Displacement Response of the Spine in Restrained PMHS during Frontal Impacts. Int. J. Automotive Eng. 5 (2), 59-64. doi:10.20485/jsaeijae.5.2_59

Davidsson, J., Deutscher, C., Hell, W., Lövsund, P., and Svensson, M. Y. (2001). Human Volunteer Kinematics in Rear-End Sled Collisions. J. Crash Prev. Inj. Control. 2 (4), 319-333. doi:10.1080/10286580008902576

Deng, B., and Wang, J. T. (2003). "Assessment of H-Model Using Volunteer Tests," in Digital Human Modeling for Design and Engineering Conference and Exhibition, June 16, 2003, Montreal, QC, 2003-01-2220. doi:10.4271/200301-2220

Doczy, E., Mosher, S., and Buhrman, J. (2004). The Effects of Variable Helmet Weight and Subject Bracing on Neck Loading during Frontal-GX Impact. Dayton, OH: GENERAL DYNAMICS ADVANCED INFORMATION SYSTEMS DAYTON OH. Available at: https://apps.dtic.mil/sti/citations/ ADA446621 (Accessed March 21, 2021).

Ejima, S., Ito, D., Satou, F., Mikami, K., Ono, K., Kaneoka, K., et al. (2012). Effects of Pre-impact Swerving/Steering on Physical Motion of the Volunteer in the LowSpeed Side-Impact Sled Test, 2012 IRCOBI Conference Proceedings (Dublin, Ireland: International Research Council on the Biomechanics of Injury), 15.

Ejima, S., Koshiro, O., Holcombe, S., Kaneoka, K., and Fukushima, M. (2007). A Study on Occupant Kinematics Behaviour and Muscle Activities during Preimpact Braking Based on Volunteer Tests. Maastricht, Netherlands: International Research Council on the Biomechanics of Injury. Available at: https://regroup-production.s3.amazonaws.com/documents/ReviewReference/ 208080904/1_2.pdf?AWSAccessKeyId=AKIAJBZQODCMKJA4H7DA \&Expires=1616359328\&Signature=tjagKdHDPBiXu\%2B\%2Be\%2Ffgug0ukqUE \%3D (Accessed March 21, 2021).

Ejima, S., Zama, Y., Satou, F., Holcombe, S., Ono, K., Kaneoka, K., et al. (2008). Prediction of the Physical Motion of the Human Body Based on Muscle Activity during Pre-impact Braking, 2008 IRCOBI Conference Proceedings (Bern, Switzerland: International Research Council on the Biomechanics of Injury), 13.

Evans, L., and Gerrish, P. H. (2001). Gender and Age Influence on Fatality Risk from the Same Physical Impact Determined Using Two-Car Crashes. Warrendale, Pennsylvania, US: SAE International. doi:10.4271/2001-01-1174

Ewing, C. L., and Thomas, D., J. (1972). Human Head and Neck Response to Impact Acceleration. Pensacola, FL: NAVAL AEROSPACE MEDICAL RESEARCH LAB PENSACOLA FL, 386.
Ewing, C. L., Thomas, D. J., Lustick, L., Becker, E., Willems, G., and Muzzy, W. H. (1975). "The Effect of the Initial Position of the Head and Neck on the Dynamic Response of the Human Head and Neck to -Gx Impact Acceleration," in 19th Stapp Car Crash Conference (1975), November 17-19, 1975, San Diego, CA, 751157. doi:10.4271/751157

Ewing, C. L., Thomas, D. J., Lustick, L., Muzzy, W. H., Willems, G. C., and Majewski, P. (1978). Effect of Initial Position on the Human Head and Neck Response to $+Y$ Impact Acceleration. Warrendale, PA: SAE Technical Paper \#780888. doi:10.4271/780888

Ewing, C. L., Thomas, D. J., Lustik, L., Muzzy, W. H., Willems, G. C., and Majewski, P. (1977). Dynamic Response of the Human Head and Neck to + Gy Impact Acceleration. Warrendale, PA: SAE Technical Papers. doi: $10.4271 / 770928$

Ewing, C. L., Thomas, D. J., Patrick, L. M., Beeler, G. W., and Smith, M. J. (1969). "Living Human Dynamic Response to -Gx Impact Acceleration IIAccelerations Measured on the Head and Neck," in 13th Stapp Car Crash Conference (1969) (Warrendale, Pennsylvania, US: SAE International). doi:10.4271/690817

Fryar, C. D., Carroll, M. D., Gu, Q., Afful, J., and Ogden, C. L. (2021). Anthropometric Reference Data for Children and Adults : United States, 2015-2018. Available at: https://stacks.cdc.gov/view/cdc/100478.

Forman, J. L., Lopez-Valdes, F., Lessley, D. J., Riley, P., Sochor, M., Heltzel, S., et al. (2013). "Occupant Kinematics and Shoulder Belt Retention in Far-Side Lateral and Oblique Collisions: A Parametric Study," in 57th Stapp Car Crash Conference, November 11-13, 2013, Orlando, FL, 201322-0014. doi:10.4271/2013-22-0014

Foster, J., Kortge, J., and Wolanin, M. (1977). Hybrid III-A BiomechanicallyBased Crash Test Dummy. SAE Trans. 86, 3268-3283. Available at: http://www. jstor.org/stable/44644622 (Accessed May 19, 2021).

Fugger, T. F., Randles, B. C., Wobrock, J. L., Welcher, J. B., Voss, D. P., and Eubanks, J. J. (2002). "Human Occupant Kinematics in Low Speed Side Impacts," in SAE 2002 World Congress \& Exhibition, March 4-7, 2002, Detroit, United States, 2002-01-0020. doi:10.4271/2002-01-0020

Funk, J. R., Cormier, J. M., Bain, C. E., Guzman, H., Bonugli, E., and Manoogian, S. J. (2011). Head and Neck Loading in Everyday and Vigorous Activities. Ann. Biomed. Eng. 39 (2), 766-776. doi:10.1007/s10439-010-0183-3

Funk, J. R., Cormier, J. M., Bain, C. E., Guzman, H., and Bonugli, E. (2009). "Validation and Application of a Methodology to Calculate Head Accelerations and Neck Loading in Soccer Ball Impacts," in SAE World Congress \& Exhibition, April 20-23, 2009, Detroit, MI, 2009-01-0251. doi:10.4271/2009-01-0251

Gepner, B. D., Joodaki, H., Sun, Z., Jayathirtha, M., Kim, T., Forman, J. L., et al. (2018). "Performance of the Obese GHBMC Models in the Sled and belt Pull Test Conditions," in IRCOBI Conference Proceedings, September 12-14, 2018, Athens, Greece.

Gutsche, A. J., Tomasch, E., Darok, M., Sinz, W., Ciglaric, I., Ravnik, D., et al. (2014). "Comparison of the Cervical Spine Bony Kinematics for Female PMHS with the Virtual EvaRID Dummy under Whiplash Loading," in Effect of Countermeasures on Adult Kinematics during Pre-crash Evasive Swerving (Berlin, Germany: International Research Council on the Biomechanics of Injury). Available at: https://regroup-production.s3.amazonaws.com/ documents/ReviewReference/208079437/32.pdf?AWSAccessKeyId= AKIAJBZQODCMKJA4H7DA\&Expires $=1616361145 \&$ Signature $=\mathrm{tVE0QuIrBNw}$ FvnP42z2fszSf6WI\%3D (Accessed March 21, 2021).

Heymsfield, S. B., Peterson, C. M., Thomas, D. M., Heo, M., Schuna, J. M., Hong, S., et al. (2014). Scaling of Adult Body Weight to Height across Sex and Race/ethnic Groups: Relevance to BMI. Am. J. Clin. Nutr. 100 (6), 1455-1461. doi:10.3945/ ajcn.114.088831

Hill, J. D., and Boyle, L. N. (2006). Assessing the Relative Risk of Severe Injury in Automotive Crashes for Older Female Occupants. Accid. Anal. Prev. 38 (1), 148-154. doi:10.1016/j.aap.2005.08.006

Holt, C., Ethan, D., Valentina, G., Thomas, S., Jason, K., Richard, K., et al. (2018). Effect of Countermeasures on Adult Kinematics during Pre-crash Evasive Swerving, 2018 IRCOBI Conference Proceedings (Lonavala, India: International Research Council on the Biomechanics of Injury), 13.

Holt, C., Seacrist, T., Douglas, E., Graci, V., Kerrigan, J., Kent, R., et al. (2020). The Effect of Vehicle Countermeasures and Age on Human Volunteer Kinematics during Evasive Swerving Events. Traffic Inj. Prev. 21 (1), 48-54. doi:10.1080/ 15389588.2019.1679798 
Humm, J. R., Yoganandan, N., Driesslein, K. G., and Pintar, F. A. (2018). Three-dimensional Kinematic Corridors of the Head, Spine, and Pelvis for Small Female Driver Seat Occupants in Near- and Far-Side Oblique Frontal Impacts. Traffic Inj. Prev. 19 (Suppl. 2), S64-S69. doi:10.1080/ 15389588.2018.1498973

Irwin, A., and Mertz, H. (1997). Biomechanical Bases for the CRABI and Hybrid III Child Dummies. SAE Trans. 106, 3551-3562. Available at: http://www.jstor. org/stable/44720132 (Accessed May 19, 2021).

Jakobsson, L., Norin, H., and Svensson, M. Y. (2004). Parameters Influencing AIS 1 Neck Injury Outcome in Frontal Impacts. Traffic Inj. Prev. 5 (2), 156-163. doi:10.1080/15389580490435989

Kallieris, D., Mattern, R., and Wismans, J. (1987). "Comparison of Human Volunteer and Cadaver Head-Neck Response in Frontal Flexion," in 31st Stapp Car Crash Conference, November 9-11, 1987, New Orleans, LA, 872194. doi:10.4271/872194

Kamibayashi, L. K., and Richmond, F. J. R. (1998). Morphometry of Human Neck Muscles. Spine 23 (12), 1314-1323. doi:10.1097/00007632-199806150-00005

Kent, R. W., Forman, J. L., and Bostrom, O. (2010). Is There Really a "Cushion Effect"?: A Biomechanical Investigation of Crash Injury Mechanisms in the Obese. Obesity 18 (4), 749-753. doi:10.1038/oby.2009.315

Klinich, K., Ebert, S., Van Ee, C., and Flannagan, C. (2004). Cervical Spine Geometry in the Automotive Seated Posture: Variations with Age, Stature, and Gender. Warrendale, PA: SAE Technical Paper No. 2004-22-0014. doi:10.4271/2004-22-0014

Krafft, M., Kullgren, A., Lie, A., and Tingvall, C. (2003). The Risk of Whiplash Injury in the Rear Seat Compared to the Front Seat in Rear Impacts. Traffic Inj. Prev. 4 (2), 136-140. doi:10.1080/15389580309862

Kullgren, A., Stigson, H., and Krafft, M. (2013). Development of Whiplash Associated Disorders for Male and Female Car Occupants in Cars Launched since the 80s in Different Impact Directions. Gothenburg, Sweden: International Research Council on the Biomechanics of Impact, 12.

Lee, S., and Bro, R. (2008). Regional Differences in World Human Body Dimensions: the Multi-Way Analysis Approach. Theor. Issues Ergon. Sci. 9, 325-345. doi:10.1080/14639220701511713

Lessley, D. J., Riley, P., Zhang, Q., Foltz, P., Overby, B., Heltzel, S., et al. (2014). Occupant Kinematics in Laboratory Rollover Tests: PMHS Response. Stapp Car Crash J. 58, 251-316. doi:10.4271/2014-22-0011

Linder, A., and Svensson, M. Y. (2019). Road Safety: the Average Male as a Norm in Vehicle Occupant Crash Safety Assessment. Interdiscip. Sci. Rev. 44 (2), 140-153. doi:10.1080/03080188.2019.1603870

Lopez-Valdes, F. J., Forman, J., Kent, R., Bostrom, O., and Segui-Gomez, M. (2009). A Comparison between a Child-Size PMHS and the Hybrid III 6 YO in a Sled Frontal Impact. Ann. Adv. Automot Med. 53, 237-246.

Lopez-Valdes, F. J., Lau, A., Lamp, J., Riley, P., Lessley, D. J., Damon, A., et al. (2010). Analysis of Spinal Motion and Loads during Frontal Impacts. Comparison between PMHS and ATD. Ann. Adv. Automot Med. 54, 61-78.

López-Valdés, F. J., Juste-Lorente, O., Maza-Frechin, M., Pipkorn, B., Sunnevang, C., Lorente, A., et al. (2016). Analysis of Occupant Kinematics and Dynamics in Nearside Oblique Impacts. Traffic Inj. Prev. 17 (Suppl. 1), 86-92. doi:10.1080/ 15389588.2016.1189077

Lopez-Valdes, F. J., Riley, P. O., Lessley, D. J., Arbogast, K. B., Seacrist, T., Balasubramanian, S., et al. (2014). The Six Degrees of Freedom Motion of the Human Head, Spine, and Pelvis in a Frontal Impact. Traffic Inj. Prev. 15 (3), 294-301. doi:10.1080/15389588.2013.817668

Margulies, S. S., Yuan, Q., and Guccione, S. J. (1998). Kinematic Response of the Neck to Voluntary and Involuntary Flexion. Aviat Space Environ. Med. 69 (9), 896.

Mathews, E. A., Balasubramanian, S., Seacrist, T., Maltese, M. R., Sterner, R., and Arbogast, K. B. (2013). Electromyography Responses of Pediatric and Young Adult Volunteers in Low-Speed Frontal Impacts. J. Electromyogr. Kinesiol. 23 (5), 1206-1214. doi:10.1016/j.jelekin.2013.06.010

Matsumoto, M., Fujimura, Y., Suzuki, N., Toyama, Y., and Shiga, H. (1998). Cervical Curvature in Acute Whiplash Injuries: Prospective Comparative Study with Asymptomatic Subjects. Injury 29 (10), 775-778. doi:10.1016/S00201383(98)00184-3

Meijer, R., van Hoof, J. F. A. M., Ono, K., Kaneoka, K., et al. (2001). “Analysis of Rear End Impact Response Using Mathematical Human Modelling and Volunteer Tests," in JSAE Spring Convention, May 23-25, 2001, Yokohama, Japan.
Mertz, H. J., Irwin, A. L., and Prasad, P. (2003). Biomechanical and Scaling Bases for Frontal and Side Impact Injury Assessment Reference Values. Stapp Car Crash J. 47, 155-188.

Morris, C. E., and Popper, S. E. (1999). Gender and Effect of Impact Acceleration on Neck Motion, Aviat Space Environ. Med. 70 (9), 851.

Ono, K., Ejima, S., Suzuki, Y., Kaneoka, K., Fukushima, M., Ujihashi, S., et al. (2006). Prediction of Neck Injury Risk Based on the Analysis of Localized Cervical Vertebral Motion of Human Volunteers during Low-Speed Rear Impacts. Madrid, Spain: Proc. IRCOBI Conf., 103-113.

Ono, K., Inami, S., Kaneoka, K., Gotou, T., Kisanuki, Y., Sakuma, S., et al. (1999). Relationship between Localized Spine Deformation and Cervical Vertebral Motions for Low Speed Rear Impacts Using Human Volunteers. Sitges, Spain: International Research Council on Biokinetics of Impact. Available at: https:// regroup-production.s3.amazonaws.com/documents/ReviewReference/ 208077264/Ono\%2C\%201999.pdf?AWSAccessKeyId=AKIAJBZQODCMKJA4H7DA \&Expires $=1616363488 \&$ Signature $=\mathrm{k} \% 2 \mathrm{FUo} 4 \mathrm{INkBR6gUaYDnPAKkLcYLGQ}$ \%3D (Accessed: March 21, 2021).

Perry, C., John, R. B., Doczy, E., Mosher, S., et al. (2003). "The Effects of Variable Helmet Weight on Head Response and Neck Loading during Lateral +Gy Impact," in The Effects of Variable Helmet Weight on Head Response and Neck Loading During Lateral +Gy Impact. 41st Annual SAFE Symposium, September 22-24, 2003, Jacksonville, FL, 8.

Petit, P., Trosseille, X., Uriot, J., Poulard, D., Potier, P., Baudrit, P., et al. (2019). Far Side Impact Injury Threshold Recommendations Based on 6 Paired WorldSID/ Post-Mortem Human Subjects Tests. Stapp Car Crash J. 63, 127-146. doi:10.4271/2019-22-0005

Petitjean, A., Lebarbe, M., Potier, P., Trosseille, X., and Lassau, J.-P. (2002). "Laboratory Reconstructions of Real World Frontal Crash Configurations Using the Hybrid III and THOR Dummies and PMHS," in 46th Stapp Car Crash Conference, November 11-13, 2002, Ponte Vedra Beach, FL, 200222-0002. doi:10.4271/2002-22-0002

Pietsch, H. A., Bosch, K. E., Weyland, D. R., Spratley, E. M., Henderson, K. A., Salzar, R. S., et al. (2016) 'Evaluation of WIAMan Technology Demonstrator Biofidelity Relative to Sub-injurious PMHS Response in Simulated Under-body Blast Events', in. 60TH Stapp Car Crash Conference, November 7-9, 2016, Washington, DC, United States, 2016-22-0009. doi:10.4271/2016-22-0009

Pintar, F. A., Yoganandan, N., and Maiman, D. J. (2010). Lower Cervical Spine Loading in Frontal Sled Tests Using Inverse Dynamics: Potential Applications for Lower Neck Injury Criteria. Stapp Car Crash J. 54, 133-166. doi:10.4271/ 2010-22-0008

Pintar, F. A., Yoganandan, N., Stemper, B. D., Bostrom, O., Rouhana, S. W., Digges, K. H., et al. (2007). Comparison of PMHS, WorldSID, and THOR-NT Responses in Simulated Far Side Impact. Stapp Car Crash J. 51, 313-360. doi:10.4271/2007-22-0014

Poulard, D., Bermond, F., and Bruyère, K. (2013). In Vivo Analysis of Thoracic Mechanical Response Variability under Belt Loading: Specific Behavior and Relationship to Age, Gender and Body Mass Index. Stapp Car Crash J. 57, 59-87. doi:10.4271/2013-22-0003

Reed, M. P., Ebert-Hamilton, S. M., and Rupp, J. D. (2012). Effects of Obesity on Seat Belt Fit. Traffic Inj. Prev. 13 (4), 364-372. doi:10.1080/ 15389588.2012.659363

Rouhana, S. W., Kankanala, S. V., Prasad, P., Rupp, J. D., Jeffreys, T. A., and Schneider, L. W. (2006). Biomechanics of 4-Point Seat Belt Systems in Farside Impacts. Stapp Car Crash J. 50, 267-298. doi:10.4271/2006-22-0012

Rupp, J. D., Flannagan, C. A. C., Leslie, A. J., Hoff, C. N., Reed, M. P., and Cunningham, R. M. (2013). Effects of BMI on the Risk and Frequency of AIS 3+ Injuries in MotorVehicle Crashes. Obesity 21 (1), E88-E97. doi:10.1002/oby.20079

Sato, F., Odani, M., Miyazaki, Y., Yamazaki, K., Östh, J., and Svensson, M. (2017). Effects of Whole Spine Alignment Patterns on Neck Responses in Rear End Impact. Traffic Inj. Prev. 18 (2), 199-206. doi:10.1080/ 15389588.2016.1227072

Seacrist, T., Locey, C. M., Mathews, E. A., Jones, D. L., Balasubramanian, S., Maltese, M. R., et al. (2014). Evaluation of Pediatric ATD Biofidelity as Compared to Child Volunteers in Low-Speed Far-Side Oblique and Lateral Impacts. Traffic Inj. Prev. 15 (Suppl. 1), S206-S214. doi:10.1080/15389588.2014.930832

Shaw, G., Lessley, D. J., Ash, J. L., Sochor, M. R., Crandall, J. R., Luzon-Narro, J., et al. (2014). Side Impact PMHS Thoracic Response with Large-Volume Air Bag. Traffic Inj. Prev. 15 (1), 40-47. doi:10.1080/15389588.2013.792109 
Shumanty, R. (2018). Mortality: Overview, 2014 to 2016, Statistics Canada. Available at: https://www150.statcan.gc.ca/n1/pub/91-209-x/2018001/article/ 54957-eng.htm (Accessed March 22, 2021).

Siegmund, G. P., Sanderson, D. J., and Inglis, J. T. (2004). Gradation of Neck Muscle Responses and Head/Neck Kinematics to Acceleration and Speed Change in Rear-End Collisions. Stapp Car Crash J. 48, 419-430. doi:10.4271/2004-22-0018

Siegmund, G. P., Blouin, J.-S., Carpenter, M. G., Brault, J. R., and Inglis, J. T. (2008). Are Cervical Multifidus Muscles Active during Whiplash and Startle? an Initial Experimental Study. BMC Musculoskelet. Disord. 9 (1), 80. doi:10.1186/14712474-9-80

Siegmund, G. P., and Blouin, J.-S. (2009). Head and Neck Control Varies with Perturbation Acceleration but Not Jerk: Implications for Whiplash Injuries. J. Physiol. 587 (8), 1829-1842. doi:10.1113/jphysiol.2009.169151

Siegmund, G. P., David, J, K., and Lawrence, J. M.(1997). "Head/neck Kinematic Response of Human Subjects in Low-Speed Rear-End Collisions," in 41st STAPP Car Crash Conference, November 13-14, 1997, Lake Buena Vista, FL, 357-385.

Siegmund, G. P., Sanderson, D. J., Myers, B. S., and Inglis, J. T. (2003a). Awareness Affects the Response of Human Subjects Exposed to a Single Whiplash-like Perturbation. Spine 28 (7), 671-679. doi:10.1097/01.BRS.0000051911.45505.D3

Siegmund, G. P., Sanderson, D. J., Myers, B. S., and Inglis, J. T. (2003b). Rapid Neck Muscle Adaptation Alters the Head Kinematics of Aware and Unaware Subjects Undergoing Multiple Whiplash-like Perturbations. J. Biomech. 36 (4), 473-482. doi:10.1016/S0021-9290(02)00458-X

Silverman, B. W. (1986). Density Estimation for Statistics and Data Analysis. London, New York: Chapman \& Hall. doi:10.1007/978-1-4899-3324-9

Stammen, J. A., Herriott, R., Kang, Y. S., Dupaix, R., and Bolte, J. (2012). Dynamic Properties of the Upper Thoracic Spine-Pectoral Girdle (UTS-PG) System and Corresponding Kinematics in PMHS Sled Tests. Stapp Car Crash J. 56, 65-104. doi:10.4271/2012-22-0003

Stark, D. B., Willis, A. K., Eshelman, Z., Kang, Y. S., Ramachandra, R., Bolte, J. H., et al. (2019). Human Response and Injury Resulting from Head Impacts with Unmanned Aircraft Systems. Stapp Car Crash J. 63, 29-64. doi:10.4271/2019-22-0002

Stemper, B. D., Yoganandan, N., Pintar, F. A., Maiman, D. J., Meyer, M. A., DeRosia, J., et al. (2008). Anatomical Gender Differences in Cervical Vertebrae of Size-Matched Volunteers. Spine 33 (2), E44-E49. doi:10.1097/ BRS.0b013e318160462a

Sundararajan, S., Rouhana, S. W., Board, D., DeSmet, E., Prasad, P., Rupp, J. D., et al. (2011). Biomechanical Assessment of a Rear-Seat Inflatable Seatbelt in Frontal Impacts. Stapp Car Crash J. 55, 161-197. doi:10.4271/2011-22-0008

Symeonidis, I., Kavadarli, G., Erich, S., Graw, M., and Peldschus, S. (2012). Analysis of the Stability of PTW Riders in Autonomous Braking Scenarios. Accid. Anal. Prev. 49, 212-222. doi:10.1016/j.aap.2011.07.007

US Census Bureau (2021). Available at: https://www2.census.gov/programssurveys/popest/tables/2010-2019/national/asrh/nc-est2019-syasexn.xlsx. (Accessed February 2, 2021).

van den Kroonenberg, A., Philippens, M., Cappon, H., Wismans, J., et al. (1998). "Human Head-Neck Response during Low-Speed Rear End Impacts," in 42nd Annual Stapp Car Crash Conference (Tempe, Arizona, USA: Society of Automotive Engineers, Inc., Warrendale, Pennsylvania, USA), 1-16.

van Rooij, L., Elrofai, H., Philippens, M. M., and Daanen, H. A. (2013). Volunteer Kinematics and Reaction in Lateral Emergency Maneuver Tests. Stapp Car Crash J. 57, 313-342.

Vasavada, A. N., Danaraj, J., and Siegmund, G. P. (2008). Head and Neck Anthropometry, Vertebral Geometry and Neck Strength in Height-Matched Men and Women. J. Biomech. 41 (1), 114-121. doi:10.1016/j.jbiomech.2007.07.007
Vezin, P., Bruyere-Garnier, K., Bermond, F., and Verriest, J. P. (2002) "Comparison of Hybrid III, Thor- $a$ and PMHS Response in Frontal Sled Tests," in 46th Stapp Car Crash Conference, November 11-13, 2002, Ponte Vedra Beach, FL, 2002-22-0001. doi:10.4271/2002-22-0001

Vezin, P., and Verriest, J. P. (2003). Influence of the Impact and Restraint Conditions on Human Surrogate Head Response to a Frontal Deceleration, 2003 IRCOBI Conference Proceedings (Lisbon, Portugal: International Research Council on the Biomechanics of Injury), 18.

Viano, D. C. (2003). Seat Influences on Female Neck Responses in Rear Crashes: A Reason Why Women Have Higher Whiplash Rates. Traffic Inj. Prev. 4 (3), 228-239. doi:10.1080/15389580309880

White, N. A., Begeman, P. C., Hardy, W. N., Yang, K. H., Ono, K., Sato, F., Kamiji, K., Yasuki, T., and Bey, M. J. (2009). "Investigation of Upper Body and Cervical Spine Kinematics of Post Mortem Human Subjects (PMHS) during Low-Speed, Rear-End Impacts," in SAE World Congress \& Exhibition, April 20-23, 2009, Detroit, MI, 2009-010387. doi:10.4271/2009-01-0387

Wiechel, J., and Bolte, J. (2006). "Response of Reclined Post Mortem Human Subjects to Frontal Impact," in SAE 2006 World Congress \& Exhibition, April 3-6, 2006, Detroit, MI, United States, 2006-01-0674. doi:10.4271/2006-01-0674

Yoganandan, N., Chirvi, S., Voo, L., Pintar, F. A., and Banerjee, A. (2018). Role of Age and Injury Mechanism on Cervical Spine Injury Tolerance from Head Contact Loading. Traffic Inj. Prev. 19 (2), 165-172. doi:10.1080/ 15389588.2017.1355549

Yoganandan, N., and Pintar, F. (2000). "Biomechanics of Human Occupants in Simulated Rear Crashes: Documentation of Neck Injuries and Comparison of Injury Criteria," in 44th Stapp Car Crash Conference, April 6-8, 2000, Atlanta, GA, 2000-2001-SC14. doi:10.4271/2000-01-SC14

Yukawa, Y., Kato, F., Suda, K., Yamagata, M., and Ueta, T. (2012). Age-related Changes in Osseous Anatomy, Alignment, and Range of Motion of the Cervical Spine. Part I: Radiographic Data from over 1,200 Asymptomatic Subjects. Eur. Spine J. 21 (8), 1492-1498. doi:10.1007/s00586-012-2167-5

Zaseck, L. W., Anne, C. B., Carl, S. M., Nichole, R. O., Matthew, P. R., Constantine, K. D., et al. (2019). Kinematic and Biomechanical Response of Post-Mortem Human Subjects under Various Pre-impact Postures to High-Rate Vertical Loading Conditions. Stapp Car Crash J. 63, 235. doi:10.4271/2019-22-0010

Zhu, S., Layde, P. M., Guse, C. E., Laud, P. W., Pintar, F., Nirula, R., et al. (2006). Obesity and Risk for Death Due to Motor Vehicle Crashes. Am. J. Public Health 96 (4), 734-739. doi:10.2105/AJPH.2004.058156

Conflict of Interest: The authors declare that the research was conducted in the absence of any commercial or financial relationships that could be construed as a potential conflict of interest.

Publisher's Note: All claims expressed in this article are solely those of the authors and do not necessarily represent those of their affiliated organizations, or those of the publisher, the editors and the reviewers. Any product that may be evaluated in this article, or claim that may be made by its manufacturer, is not guaranteed or endorsed by the publisher.

Copyright (๑) 2021 Booth, Cripton and Siegmund. This is an open-access article distributed under the terms of the Creative Commons Attribution License (CC BY). The use, distribution or reproduction in other forums is permitted, provided the original author(s) and the copyright owner(s) are credited and that the original publication in this journal is cited, in accordance with accepted academic practice. No use, distribution or reproduction is permitted which does not comply with these terms. 